\title{
Acute inflammatory response secondary to intrapleural administration of two types of
} talc

\author{
V.F. Rossi, F.S. Vargas, E. Marchi, M.M.P. Acencio, E.H. Genofre, \\ V.L. Capelozzi and L. Antonangelo
}

ABSTRACT: Intrapleural instillation of talc has been used in the treatment of recurrent pleural effusions but can, in rare instances, result in respiratory failure. Side-effects seem to be related to composition, size and inflammatory power of talc particles. The aim of this study was to evaluate the inflammatory response to intrapleural injection of talc containing small particles (ST) or talc containing particles of mixed size (MT).

100 rabbits received intrapleural talc, 50 with ST (median $6.41 \mu \mathrm{m}$ ) and 50 with MT (median $21.15 \mu \mathrm{m}$ ); the control group was composed of 35 rabbits. Cells, lactate dehydrogenase, Creactive protein (CRP), interleukin (IL)-8 and vascular endothelial growth factor were evaluated in serum and bronchoalveolar lavage at 6, 24, 48, 72 and $96 \mathrm{~h}$.

Lung histology and the presence of talc were also analysed. Statistics were performed using ANOVA and an unpaired t-test. Most of the parameters showed greater levels in the animals injected with talc than in the controls, suggesting a systemic and pulmonary response. Higher serum levels of CRP and IL-8 were observed in the animals injected with ST. Talc particles were observed in both lungs with no differences between groups. Lung cell infiltrate was more evident in the ST group.

In conclusion, talc with larger particles should be the preferred choice in clinical practice in order to induce safer pleurodesis.

KEYWORDS: Bronchoalveolar lavage, cytokine production, inflammatory mediators, pleurodesis, rabbits

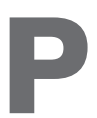

atients with malignant pleural disease frequently present with recurrent pleural effusion, justifying the recommendation of pleurodesis. Among the proposed sclerosing agents, talc is the most frequently used as it is widely available, inexpensive and highly efficacious [1-7]. However, despite common use, its administration may be questionable due to the development of undesirable side-effects [3, 7-12].

It is important to bear in mind that talc particles have been found in samples obtained from bronchoalveolar lavage (BAL) and pulmonary tissues of patients undergoing pleurodesis $[7,11]$. It is believed that, starting from the pleural cavity, talc particles migrate to the pulmonary parenchyma through the stomas of the parietal pleura before reaching the systemic circulation and then later return to the lungs [13]. Another pathway of dissemination is through the mesothelial layer by rupture or invagination of the intercellular spaces of the visceral pleura, before reaching the adjacent pulmonary parenchyma [14, 15]. In this scenario, the smaller the particle the higher the chance of migration. In fact, countries where smaller talc particles are used, in general present a greater incidence of respiratory failure following pleurodesis [16]. However, contradictory to these facts, in the literature there is a necroscopic reference to a patient who died as a result of respiratory failure after undergoing pleurodesis, with no evidence of systemic migration of talc [12]. This study allows us to consider the existence of other mechanisms, one being the composition of the talc itself. In this case, the local inflammatory reaction could have contributed to an unfavourable outcome as a result of the production of inflammatory markers which could reach the pulmonary parenchyma by the visceral pleura or which could produce a systemic response and, later on, an acute pulmonary response [12].

\section{AFFILIATIONS}

Laboratory of Pleura, Pulmonary Division, Heart Institute (InCor), LIMs 3 and 9, University of São Paulo Medical School, São Paulo, Brazil.

CORRESPONDENCE

F.S. Vargas

R Itapeva 500

cjto 4C

Bela Vista

São Paulo

01332-000

Brazil

E-mail: pnevargas@incor.usp.br

Received:

March 092009

Accepted after revision:

July 072009

First published online:

Aug 132009
European Respiratory Journal Print ISSN 0903-1936

Online ISSN 1399-3003 


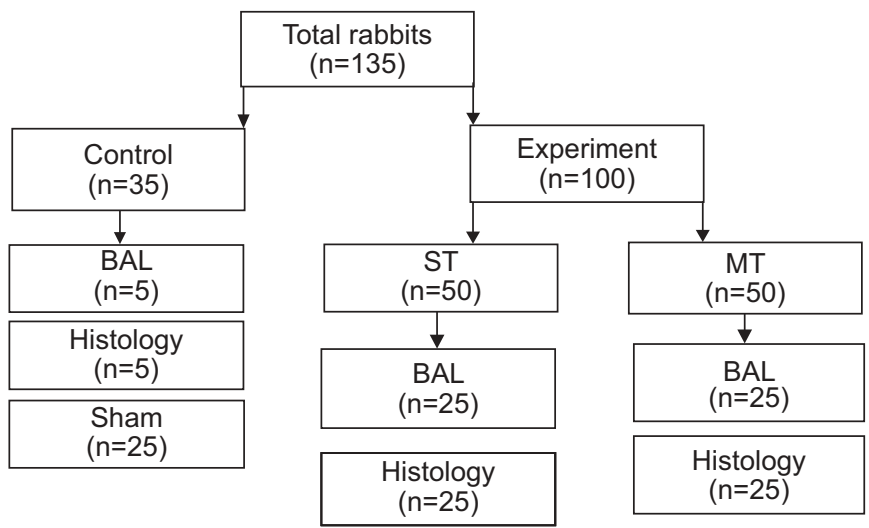

FIGURE 1. Distribution of rabbits in the experiment. BAL: bronchoalveolar lavage; ST: talc containing small particles; MT: talc containing particles of mixed size.

In this case, even though the dissemination of talc is recognised, there are few clinical or experimental studies evaluating the response of inflammatory markers in the BAL [17]. Thus, the aim of this study is to analyse, in an experimental model, the pulmonary and systemic changes secondary to the intrapleural administration of different sizes of talc particles.

\section{MATERIALS AND METHODS}

The study was approved by the local ethics committee (Hospital das Clinicas, University of São Paulo Medical School, São Paulo, Brazil) and was conducted in the laboratory of pleural diseases (University of São Paulo Medical School).

135 New Zealand rabbits $(2-3 \mathrm{~kg})$ were divided in two groups: control $(n=35)$ and experimental $(n=100)$ (fig. 1). In the control group, five animals underwent only BAL (simple control); five were used for lung histological analysis (control without undergoing BAL) and 25 underwent an intrapleural injection of saline with BAL (sham control). The experimental group $(n=100)$ received an intrapleural injection of talc $\left(400 \mathrm{mg} \cdot \mathrm{kg}^{-1}\right)$ diluted in saline in the right hemithorax. Of these, 50 animals received calibrated talc and 50 received talc containing particles of mixed size (MT), as used in clinical practice. A sampling of BAL was collected from 25 animals in each subgroup. Of the remainder $(n=25), B A L$ was not carried out, to avoid interference in the histological analysis of the lungs. The calibrated talc was predominantly talc containing small particles (ST) and was supplied by Sigma Aldrich (Steinheim, Germany); the MT was supplied by Magnesita (São Paulo, Brazil). The composition and the size of the particles are shown in table 1.

Prior to carrying out these procedures, the animals were sedated by an intramuscular injection of ketamine chlorohydrate $\left(35 \mathrm{mg} \cdot \mathrm{kg}^{-1}\right)$ and xylazine chlorohydrate $\left(5 \mathrm{mg} \cdot \mathrm{kg}^{-1}\right)$. For euthanasia, pentobarbital $\left(60 \mathrm{mg} \cdot \mathrm{kg}^{-1}\right)$ was injected in the marginal vein of the ear after $6,24,48,72$ or $96 \mathrm{~h}$ of intrapleural injection of talc. Immediately after this procedure, the abdominal cavity was opened and a blood sample was taken from the inferior vein cava.

\begin{tabular}{|c|c|c|}
\hline TABLE 1 & $\begin{array}{l}\text { Elemental composition an } \\
\text { talc }\end{array}$ & of particles in \\
\hline Talc & Small particles & Mixed particles \\
\hline \multicolumn{3}{|c|}{ Elemental composition } \\
\hline Silica & 64.754 & 69.746 \\
\hline Magnesium & 26.799 & 26.801 \\
\hline Iron & 5.823 & 0.687 \\
\hline Aluminium & 2.137 & 2.229 \\
\hline Calcium & 0.487 & \\
\hline Chlorine & & 0.536 \\
\hline \multicolumn{3}{|l|}{ Size $\mu \mathrm{m}$} \\
\hline D10 & 2.19 & 6.66 \\
\hline D50 & 6.41 & 21.15 \\
\hline D90 & 17.82 & 52.56 \\
\hline
\end{tabular}

D10, D50 or D90: $10 \%, 50 \%$ or $90 \%$ of the particles have a smaller diameter

In order to obtain samples of the BAL, the trachea was dissected and opened. An 8-mm catheter was placed into the main bronchus to infuse $20 \mathrm{~mL}$ of physiological solution, first to the left and then to the right side, to avoid mixing the BAL samples. For the histological analysis of the lungs, the thorax was removed en bloc and 10\% formalin was injected through the trachea to avoid the lungs collapsing.

The cytological study included a haemogram and quantitative analysis of the BAL. Measurements of lactate dehydrogenase (LDH; semi-automated ultraviolet kinetic method), urea (colorimetric assay) and C-reactive protein (CRP; immunoaglutination) were carried out in blood and lavage supernatant.

Samples were stored at $-80^{\circ} \mathrm{C}$ for further measurement of the cytokines interleukin (IL)-8 (Opt EIA; Pharmingen, San Diego, CA, USA) and vascular endothelial growth factor (VEGF; R\&D Systems, Minneapolis, MN, USA), which were measured using ELISA. In order to correct the concentration of the biochemical parameters analysed in the BAL, the relationship between serum and BAL urea was used [18, 19]. Histological analysis of the pulmonary parenchyma included the semi-quantitative evaluation of cellular infiltrate, oedema, capillaritis, haemorrhage and thrombosis, which are parameters associated with acute respiratory distress syndrome (ARDS). The evaluation was performed by two independent pathologists (L. Antonangelo and V.L. Capelozzi), who were blinded to allocation. 10 randomised fields were analysed and the results were expressed as a score (0-3) according to the degree of pulmonary impairment [20].

\section{Statistical analysis}

Data are expressed as median (25\% and $75 \%$ quartile) or mean $\pm S D$, depending on the distribution of the samples. To compare the results obtained with both types of talc, an unpaired t-test or Mann-Whitney test was used. In order to compare the findings from the right and left lungs, we used the paired t-test (normal distribution) or Wilcoxon test (nonnormal distribution). The temporal analysis of the variables was carried out by ANOVA. The Tukey test or Dunn multiple comparison test was used when significant differences were 


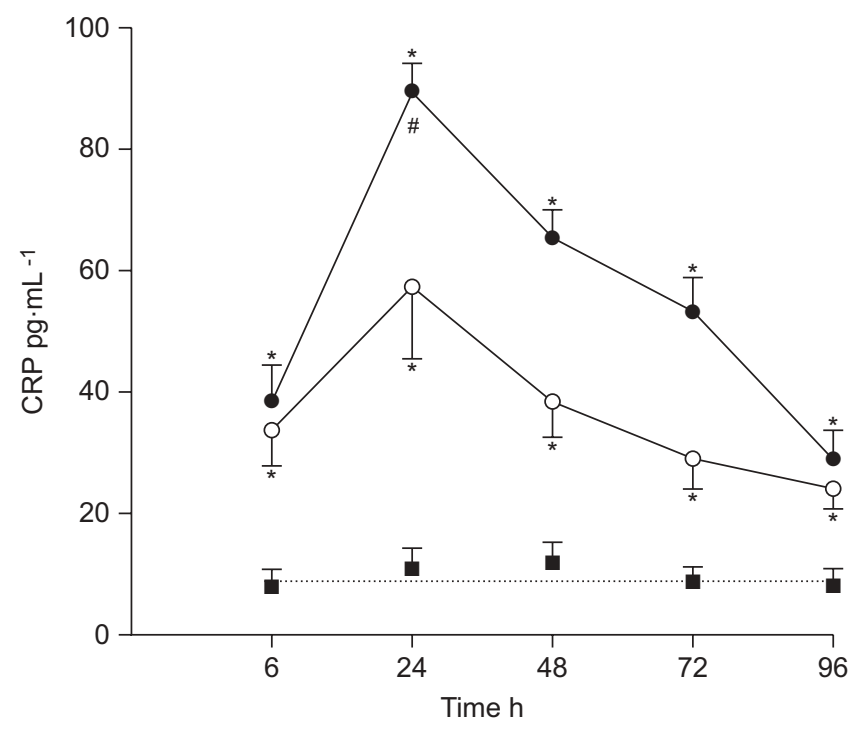

FIGURE 2. C-reactive protein (CRP) levels in the blood of rabbits undergoing intrapleural injection of talc containing small particles (ST; $\bullet$ ) or talc containing particles of mixed size (MT; $\bigcirc)$. $\mathbf{\square}$ : sham. ........... Control. *: $p<0.05$ compared with sham or control groups; ${ }^{*}: \mathrm{p}<0.05$ between ST and MT.

found $(\mathrm{p}<0.05)$. The SigmaStat program (SPSS, San Raphael, CA, USA) was used for statistical analysis.

\section{RESULTS}

No significant differences were observed between sham and simple controls (figs 2-4).

The leukocyte count and LDH (blood and BAL) measurement did not reveal significant differences between both types of talc and the control group, not even between the left and right lungs (BAL).

Compared with the control group, after $6 \mathrm{~h}$ the animals injected with talc showed a marked increase in serum CRP levels, which remained high throughout the whole study period ( $96 \mathrm{~h}$ ), reaching their highest value after $24 \mathrm{~h}$ of the procedure. The ST induced a greater systemic inflammatory response, with statistical significance after $24 \mathrm{~h}$ of administration (fig. 2). Levels of CRP were untraceable in the BAL of both study groups.

Among the groups that received talc, the serum levels of VEGF increased after $24 \mathrm{~h}$ and remained high throughout the whole evaluated period. This increase was independent of the size of the particles. In relation to BAL, both lungs presented high VEGF levels after $6 \mathrm{~h}$ of intrapleural injection, which remained high during the $96 \mathrm{~h}$ with no significant differences between the two types of talc. It should be noted that in the first $72 \mathrm{~h}$ the BAL from the right lung (injected side) presented higher VEGF levels than the side that had not been injected (fig. 3).

In relation to IL-8, in both types of talc the serum levels remained high throughout the study period. At all times when analysing the BAL, we observed higher levels on the right side than in the control. Compared with the MT, animals injected with ST presented with higher levels at 72 and $96 \mathrm{~h}$. The injection of talc did not cause significant differences in the levels of IL-8 on both BAL sides. On the left side, animals injected with ST presented with higher levels of IL-8 at all times, a fact observed from $24 \mathrm{~h}$ in the animals injected with MT (fig. 4).

Based on the histological evaluation, we did not observe significant differences between the two experimental groups for most of the parameters. Only the cellular infiltrate was more pronounced from $48 \mathrm{~h}$ onwards in animals injected with ST (fig. 5).

\section{DISCUSSION}

We observed that when injected in the pleural cavity both types of talc produce an acute pulmonary and systemic inflammatory response which tends to be more pronounced in the animals injected with ST.

Previous studies have shown that talc particles could be found in the BAL and lung tissue of patients undergoing pleurodesis $[7,11]$. Among the factors related to the inflammatory response some, such as the size, composition of the talc particles and the injected dose, should be taken into consideration $[7,11,16,17$, 20]. Our study supports the observation that early clinical manifestation, in particular acute respiratory failure, appears in the first $96 \mathrm{~h}$ following the procedure. In the present study,

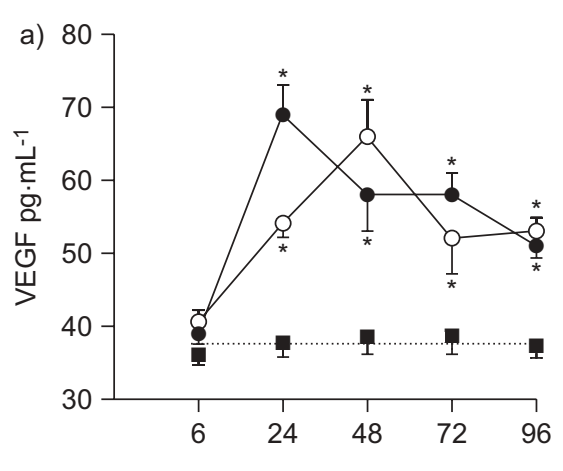

Time $\mathrm{h}$

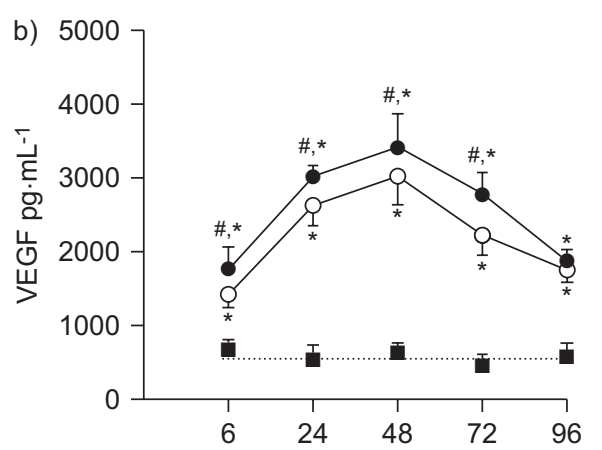

Time $\mathrm{h}$

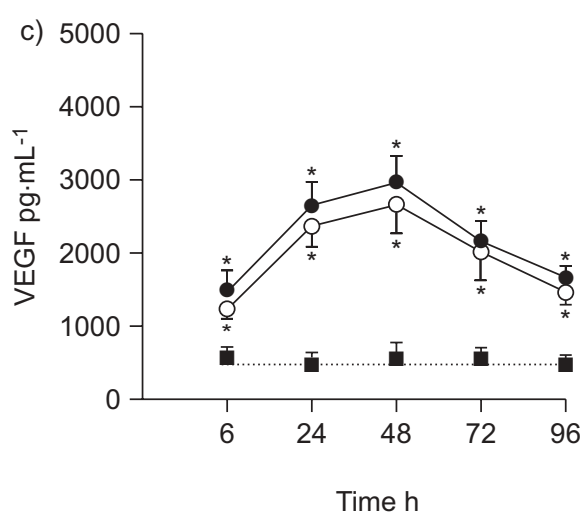

FIGURE 3. Vascular endothelial growth factor (VEGF) levels in blood and bronchoalveolar lavage (BAL) of rabbits undergoing intrapleural injection of talc containing small particles $(\bullet)$ or talc containing particles of mixed size $(\bigcirc)$. a) Blood, b) right BAL and c) left BAL. Comparison with the control group $(\cdots \cdots \cdot)$ and between the right and left sides. $\mathbf{a}$ : sham. *: $p<0.05$ compared with sham or control groups; ${ }^{*}: p<0.05$ between left and right sides. 

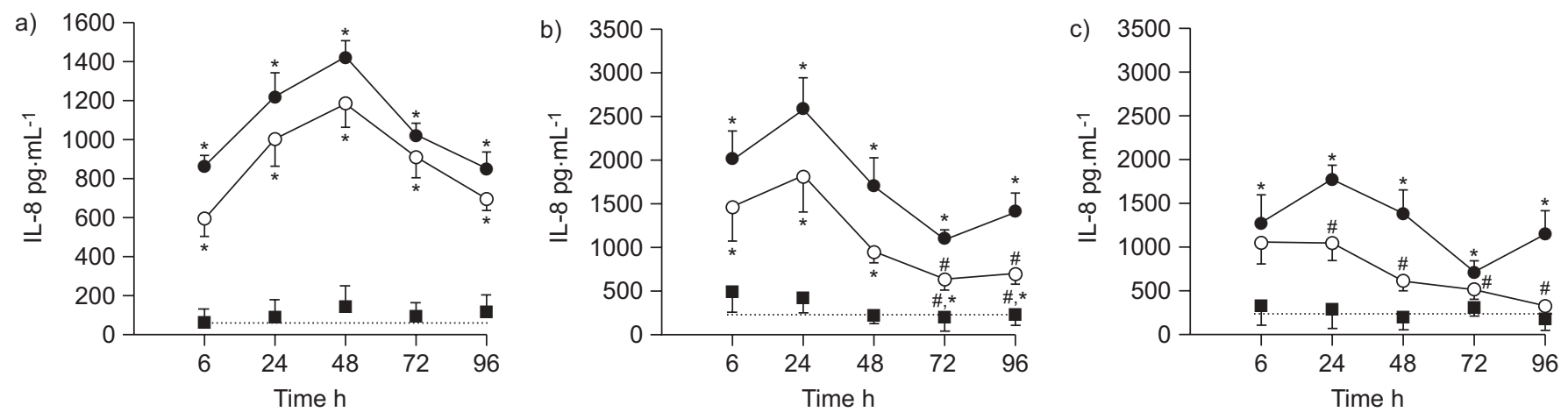

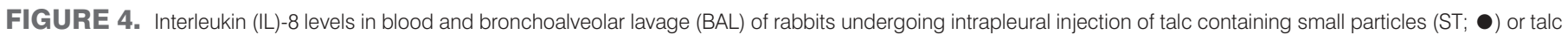

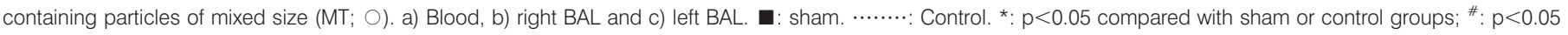
between ST and MT.

both types of talc produced an acute inflammatory response: blood levels of CRP, VEGF and IL-8 increased in the first $48 \mathrm{~h}$ of the procedure, with a fall at the subsequent time intervals. BAL presented a similar response for VEGF and IL-8.

The maximum levels of IL-8 (BAL) were obtained after $24 \mathrm{~h}$ of intrapleural injection. In the serum this behaviour was noted after $24 \mathrm{~h}$, suggesting that the pulmonary inflammatory response precedes the systemic one. Similar results were observed by GENOFRE et al. [21], who cited this behaviour after analysing blood and pleural fluid in rabbits undergoing to talc pleurodesis.

It is of interest to note that the ST induced a more pronounced inflammatory response as demonstrated by the increasing CRP and IL-8 levels. MASKELL et al. [22] evaluated the alveolararterial pressure gradient of oxygen and CRP and also showed the presence of a more evident systemic and pulmonary inflammation after using ST.

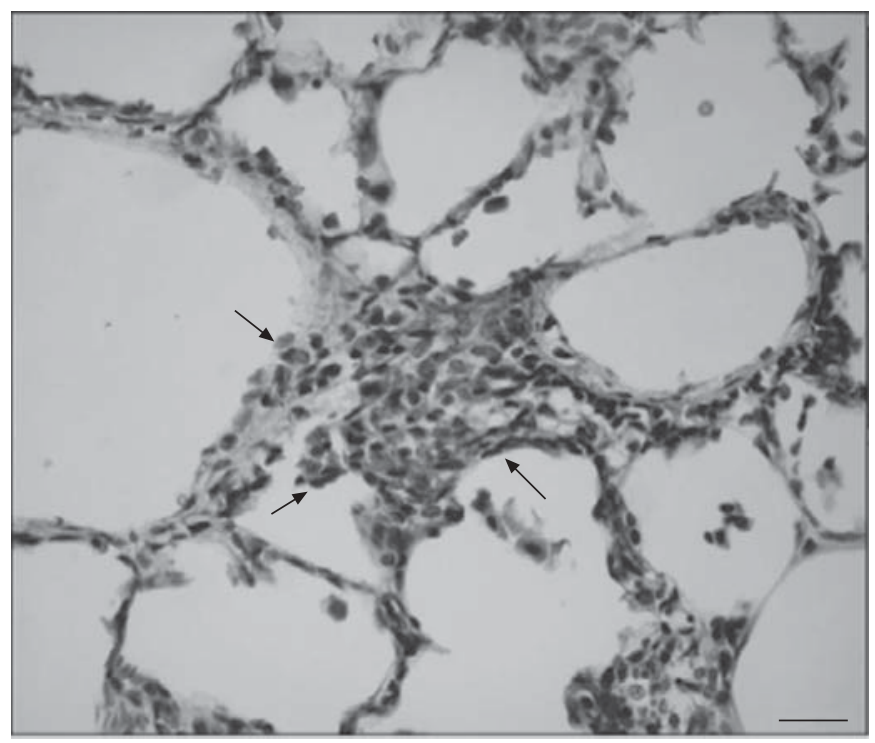

FIGURE 5. Photomicrography of lung parenchyma of rabbits injected with talc containing small particles. The presence of lymphomononuclear infiltrate is shown by arrows. Haematoxylin and eosin. Scale bar $=10 \mu \mathrm{m}$.
Evaluation of the pulmonary response showed an increase in BAL levels of VEGF and IL-8. No significant differences were observed between the IL-8 levels in both lungs; however, VEGF showed higher levels in the right lung of animals injected with ST. These results suggest that the overflow of inflammatory mediators from the pleura, the first site of injury, can stimulate pulmonary production of these mediators within the pulmonary circulation before they reach the blood stream. This hypothesis could explain the case reported by GILL et al. [12] in which a patient undergoing pleurodesis with talc developed lung failure and died, but no talc particles were found in the necropsy examination.

In order to compare the IL- 8 and VEGF levels (blood and BAL) we used a factor to correct the BAL dilution. We obtained higher levels of IL-8 and VEGF in the fluid covering the alveoli than in blood, suggesting, once more, that the lung is the target organ in the inflammatory response induced by intrapleural talc injection. The correlations between IL-8 and VEGF levels in both talc groups (ST and MT) and in both hemithoraces reflect an acute shared response of the lungs to pleural injury. Despite the higher levels of IL- 8 and VEGF seen on the right side, the positive correlations suggest that after injection the lungs react to injury in a unique way.

In the blood, the leukocyte count and the IL- 8 and VEGF levels were similar to those observed in previous studies, reflecting a more pronounced response to the injection of ST [23, 24]. When we analyse these results in the light of ARDS, some observations can be made and questions raised. According to MEDURI et al. [25], the majority of patients with ARDS, irrespective of their aetiology, presented with higher serum levels of IL-8, IL-1 $\beta$ and IL- 6 over the first $24 \mathrm{~h}$ following the onset of clinical manifestation. Individuals who maintain high levels of these markers generally die, whereas those who present a reduction of these levels after $48 \mathrm{~h}$ almost always have a favourable outcome. In the present study, the rise and fall of these markers were similar to those described by MEDURI et al. [25]. Despite IL-8 levels (blood and BAL) remaining high during the experimental period, none of the animals showed signs compatible with ARDS. However, increased levels of IL-8 (blood and BAL) in the animals of the ST group suggest that the particle size influences the inflammatory response. The 

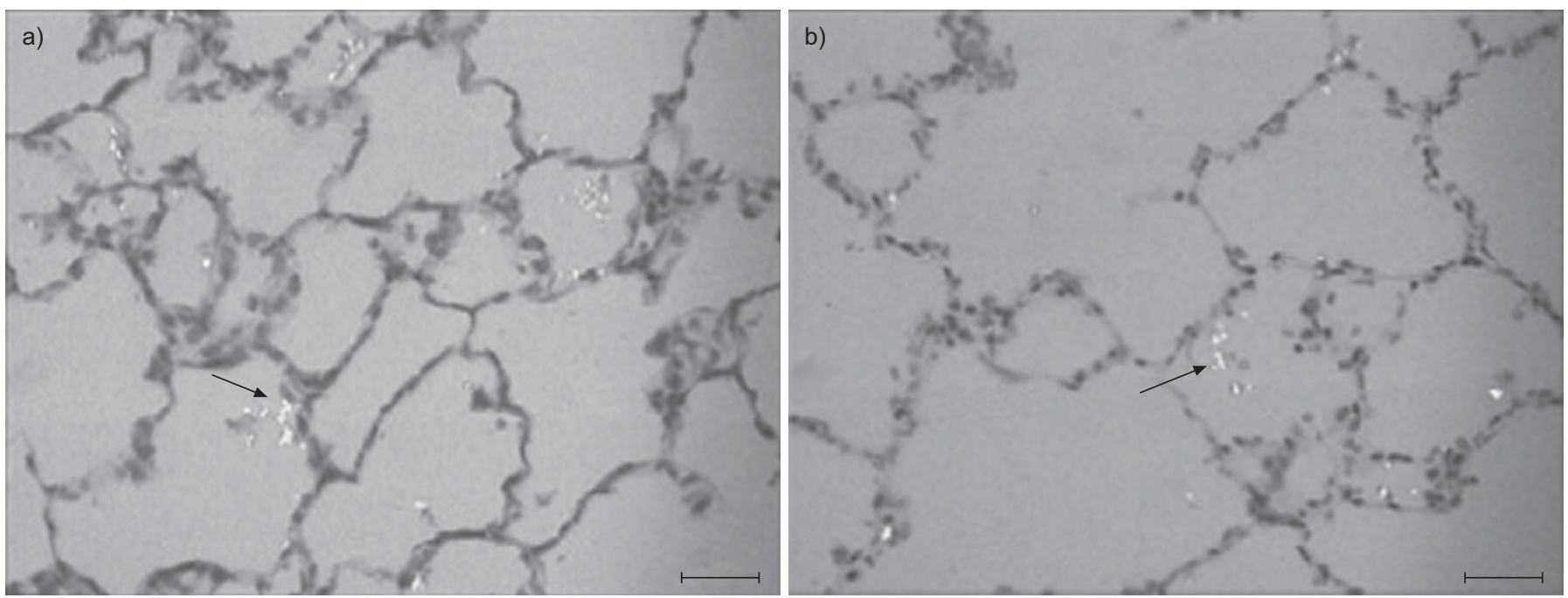

FIGURE 6. Photomicrography of lung parenchyma of rabbits injected with talc containing a) small particles or b) particles of mixed size. The arrows show the presence of talc particles. Haematoxylin and eosin, polarised light microscopy. Scale bars $=30 \mu \mathrm{m}$.

mechanisms by which this response occurs have not been fully clarified and need more investigation.

The presence of talc particles in intra- and extrathoracic organs has also been a topic of study. FERRER et al. [16] suggest that the small particles may cross the pleural lymphatic stomas $(6.2 \mu \mathrm{m}$ in humans) reaching the lymphatic blood vessels before the systemic circulation and inducing a systemic and pulmonary inflammatory response. In our study, both sizes of talc particles were observed in the lungs, although with no significant difference between the groups (fig. 6). These findings permit us to speculate that migration of talc to the lungs may occur through the systemic circulation. Nevertheless, we must reiterate the limitations of the method used to quantify talc particles. The digital image analysis system used does not enable us to detect particles $>2 \mu \mathrm{m}$ in size. As these particles are more common in the ST, this quantity may be underestimated, leading to an erroneous conclusion that the dispersion of talc was similar in both groups.

The histological changes were discrete and similar in both study groups (ST and MT). Only the lymphomononuclear infiltrate showed a tendency to be more pronounced in animals injected with ST. As none of the animals developed ARDS, we interpreted this finding as part of the acute inflammatory response triggered by the lungs.

Finally, it should be reiterated that although the talc may be mainly composed of silica and magnesium, other chemical elements may be present. In this study, despite the similar composition of both types of talc, the ST had a higher percentage of iron. Experimental studies using asbestos fibres with iron (crocidolite) have shown an increase in the inflammatory response and greater cellular damage [26, 27]. However, we do not know of studies linking the chemical composition of talc to the inflammatory response observed in pleurodesis or with triggering ARDS.

In conclusion, this study reinforces the use of calibrated talc with larger particles in the clinical practice for induction of pleurodesis. The intent is to make the procedure safer and free from adverse effects, including death.

\section{SUPPORT STATEMENT}

This study was supported by the São Paulo Research Foundation (FAPESP) and the Brazilian National Council of Research (CNPq) (both Brazil).

\section{STATEMENT OF INTEREST}

None declared.

\section{REFERENCES}

1 Lee YC, Baumann MH, Maskell NA, et al. Pleurodesis practice for malignant pleural effusions in five English-speaking countries. Survey of pulmonologists. Chest 2003; 124: 2229-2238.

2 Kennedy L, Sahn SA. Talc pleurodesis for the treatment of pneumothorax and pleural effusion. Chest 1994; 106: 1215-1222.

3 Kennedy L, Rusch VW, Strange C, et al. Pleurodesis using talc slurry. Chest 1994; 106: 342-346.

4 Vargas FS, Wang NS, Teixeira LR, et al. Corynebacterium parvum versus tetracycline as pleural sclerosing agents in rabbits. Eur Respir J 1995; 8: 2174-2177.

5 Paschoalini MS, Vargas FS, Marchi E, et al. Prospective randomized trial of silver nitrate $v s$ talc slurry in pleurodesis for symptomatic malignant pleural effusions. Chest 2005; 128: 684-689.

6 Montes JF, Ferrer J, Villarino MA, et al. Influence of talc dose on extrapleural talc dissemination after talc pleurodesis. Am J Respir Crit Care Med 2003; 168: 348-355.

7 Campos JR, Vargas FS, de Campos Werebe E, et al. Thoracoscopy talc poudrage. A 15-year experience. Chest 2001; 119: 801-806.

8 Rinaldo JE, Owens GR, Rogers RM. Adult respiratory distress syndrome following intrapleural instillation of talc. $J$ Thorac Cardiovasc Surg 1983; 85: 523-526.

9 Rehse DH, Aye RW, Florence MG. Respiratory failure following talc pleurodesis. Am J Surg 1999; 177: 437-440.

10 Dresler CM, Olak J, Herndon JE 2nd, et al. Phase III Intergroup study of talc poudrage $v$ s talc slurry sclerosis for malignant pleural effusion. Chest 2005; 127: 909-915.

11 Campos JR, Werebe EC, Vargas FS, et al. Respiratory failure due to insufflated talc. Lancet 1997; 349: 251-252. 
12 Gill AJ, Mathur MN, Tattersall SF. Systematic response to talc pleurodesis. Coment. Am J Respir Crit Care Med 2004; 169: 1074-1075.

13 Wang QX, Ohtani O, Saitoh M, et al. Distribution and ultrastructure of the stomata connecting the pleural cavity with lymphatics in the rat costal pleura. Acta Anat 1997; 158: 255-265.

14 Takada K, Otsuky Y, Magari S. Lymphatics and pre-lymphatics of the rabbit pericardium and epicardium with special emphasis on particulate absorption and milk spot-like structures. Lymphology 1991; 24: 116-124.

15 Miserocchi G. Physiology and pathophysiology of pleural fluid turnover. Eur Respir J 1997; 10: 219-225.

16 Ferrer J, Montes JF, Villarino MA, et al. Influence of particle size on extrapleural talc dissemination after talc slurry pleurodesis. Chest 2002; 122: 1018-1027.

17 Werebe EC, Pazetti R, Milanez de Campos JR, et al. Systemic distribution of talc after intrapleural administration in rats. Chest 1999; 115: 190-193.

18 Rennard SI, Basset G, Lecossier D, et al. Estimation of volume of epithelial lining fluid recovered by lavage using urea as marker of dilution. J Appl Physiol 1986; 60: 532-538.

19 Orphanidou D, Stratakos G, Rasidakis A, et al. Adenosine deaminase activity and lysosyme levels in bronchoalveolar lavage fluid in patients with pulmonary tuberculosis. Int J Tuberc Lung Dis 1998; 2: 147-152.
20 Vargas FS, Teixeira LR, Antonangelo L, et al. Experimental pleurodesis in rabbits induced by silver nitrate or talc: 1-year follow-up. Chest 2001; 119: 1516-1520.

21 Genofre EH, Vargas FS, Acencio MMP, et al. Talc pleurodesis: evidence of systemic inflammatory response to small size talc particles. Respir Med 2009; 103: 91-97.

22 Maskell NA, Lee YC, Gleeson FV, et al. Randomized trials describing lung inflammation after pleurodesis with talc of varying particle size. Am J Respir Crit Care Med 2004; 170: 377-382.

23 Marchi E, Vargas FS, Acencio MMP, et al. Talc and silver nitrate induce systemic inflammatory effects during the acute phase of experimental pleurodesis in rabbits. Chest 2004; 125: 2268-2277.

24 Marchi E, Vargas FS, Teixeira LR, et al. Intrapleural low-dose silver nitrate elicits more pleural inflammation and less systemic inflammation than low dose talc. Chest 2005; 128: 1798-1804.

25 Meduri GU, Kohler G, Headley S, et al. Inflammatory cytokines in the BAL of patients with ARDS. Persistent elevation over time predicts poor outcome. Chest 1995; 108: 1303-1314.

26 Choe N, Tanaka S, Kagan E. Asbestos fibers and interleukin-1 upregulate the formation reactive nitrogen species in rat pleural mesothelial cells. Am J Respir Cell Mol Biol 1998; 19: 226-236.

27 Liu W, Ernst JD, Broaddus VC. Phagocytosis of crocidolite asbestos induces oxidative stress, DNA damage, and apoptosis in mesothelial cells. Am J Respir Cell Mol Biol 2000; 23: 371-378. 